\title{
Is There Still a Role for Glycoprotein Ilb/llla Antagonists in Acute Coronary Syndromes?
}

\author{
Loredana Iannetta ${ }^{\mathrm{a}}$, Paolo Emilio Puddu ${ }^{\mathrm{a}, \mathrm{c}}$, Domenico Cuturello ${ }^{\mathrm{a}}$, Angela Saladini ${ }^{\mathrm{b}}$, \\ Mariano Pellicano ${ }^{a}$, Michele Schiariti ${ }^{\mathrm{a}}$
}

\begin{abstract}
The role played by glycoprotein (GP) IIb/IIIa inhibitors has continuously evolved from the initial introduction in mid $90 \mathrm{~s}$ until the most recent guidelines for treating acute coronary syndromes, and competed with a wider use of ADP inhibitors and novel anticoagulant drugs, to the extent that they stepped down from class I to class II recommendation in the routine setting of acute coronary syndromes. As a consequence, GP IIb/IIIa use was greatly narrowed. The purpose of this review is to define the roles that GP $\mathrm{IIb} / \mathrm{III}$ inhibitors may still have in acute ischemic settings by explaining why in high risk patients they might be preferable and/or whether they might be added to ADP inhibitors also emphasizing the underlying mechanistic actions. It is concluded that there might be a more extensive use of GP IIb/IIIa inhibitors in patients presenting with acute coronary syndromes, strictly based on the definition for a high risk procedure: complexity, angiographic characteristics and patient's risk profile, regardless whether STEMI or NSTEMI. The positive elements one should appreciate in GP IIb/IIIa inhibitors are: efficacy, rapid onset and reversibility of action, absence of pharmacogenomic variability, pharmacoeconomic considerations and the possibility of intracoronary administration.
\end{abstract}

Keywords: GP IIb/IIIs inhibitors; High risk patients; Acute coronary syndromes; Acute ischemia; PCI

\section{Introduction}

Platelets are smooth and discoid blood elements lacking

Manuscript accepted for publication January 30, 2013

${ }^{\mathrm{a} D e p a r t m e n t ~ o f ~ C a r d i o v a s c u l a r, ~ R e s p i r a t o r y, ~ N e p h r o l o g i c a l, ~}$ Anesthesiological and Geriatric Sciences, Sapienza, University of Rome, Italy

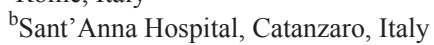

${ }^{\mathrm{c} C}$ Corresponding author: Paolo Emilio Puddu, Laboratory of Biotechnologies Applied to Cardiovascular Medicine, Department of Cardiovascular, Respiratory, Nephrological and Geriatric Sciences, Sapienza, University of Rome, Viale del Policlinico, 155, Rome 00161, Italy. Email: paoloemilio.puddu@uniroma1.it

doi: http://dx.doi.org/10.4021/cr251w several organelles of other cell compartments, but presenting essential structures whereby their role in hemostasis is fully expressed which has the counterpart of being the base for thrombotic events when stimulation is inappropriate [1]. The first step to initiate arterial thrombosis is endothelial injury and exposure of subendothelial matrix glycoprotein (GP) to circulating platelets with ensuing adhesion. Collagen seems to be the most important ligand, even if under specific conditions other molecules, for example von Willebrand Factor (vWF), play a critical role in platelet adhesion [2]. On platelet surface GPs Ia/IIa, Ic/IIa, $\alpha_{v} \beta_{3}$ and Ib/ IX mediate platelet adhesion [2]. However, platelets become activated only after they adhere to a site of injury [3]. Biochemical and mechanical mediators cause platelet activation: it seems that in the pathological setting there are upward of 100 biochemical agonists, including ADP, epinephrine, collagen and vWF $[3,4]$.

Platelet aggregation is mediated by GP IIb/IIIa binding fibrinogen and vWF and other ligands through a transition from a low to a high affinity state for its ligands, bridging platelets together [5]. Although resting platelets have a low affinity for fibrinogen, when they activate can bind more than 40,000 molecules per cell [3]. Antiplatelet therapy has been shown to significantly reduce the risk of serious vascular events in high-risk patients, including those with a prior acute ischemic event and/or ST segment elevation myocardial infarction (STEMI). Long-term antiplatelet agents are key components of secondary prevention after acute coronary syndromes (ACS), including STEMI. However, there might be a critical balance to monitor: any effective antiplatelet regimen may be closely related to increased risk for bleeding, often necessitating discontinuation of treatment and directly impinging on a potentially worse long-term outcome $[6,7]$.

The role played by GP IIb/IIIa inhibitors has continuously evolved from the initial introduction in mid 90s until the most recent guidelines for treating acute coronary syndromes, and competed with a wider use of ADP inhibitors and novel anticoagulant drugs, to the extent that they stepped down from class I to class II recommendation in the routine setting of acute coronary syndromes $[8,9]$. We then review the current role of GP IIb/IIIa inhibitors in acute ischemia 
and try to explain why in high-risk patients they might be preferable and/or might be added to ADP inhibitors which mostly rely on their underlying mechanism of action.

\section{Mechanism of Action of GP Ilb/llla Inhibitors}

The wide use of percutaneous coronary interventions (PCI) may induce a thrombotic state by injuring vessels' walls and by stimulating platelet activation and neo-intimal proliferation. In fact, acute occlusion due to stent thrombosis represented a major event causing acute myocardial infarction, cardiac death and the necessity for a new procedure or coronary by-pass intervention when coronary stents were positioned at the very beginning of their use after failure of balloon angioplasty. Antiplatelet therapy then became standard practice when coronary revascularization procedures were undertaken and aspirin played a pivotal role among these drugs since it inhibited cyclo-oxygenase enzymes, key factors in the platelets' activation pathways [10-14, 15-18]. Dual antiplatelet therapy ameliorated adverse events related to drugs used during angioplasty $[19,20]$. Pre-treatment with aspirin and ticlopidine was found to be very effective, reducing acute intra-stent thrombosis [21]. On the other hand, a two-step strategy, separating diagnostic from interventional times was selected. In fact, in the pre GP inhibitors' era, dual antiplatelet therapy was done before the patient was admitted to the catheterization laboratory since ticlopidine or clopidogrel required several days or hours before target antiplatelet effects were obtained [15-18].

GP IIb/IIIa inhibitors opened new treatment possibilities because by rapid antiplatelet action they enabled a one-step revascularization strategy, directly downstream in the catheterization laboratory [15-18]. Because of the low affinity for ligands in resting platelets and its increase after platelets are activated, being GP IIb/IIIa the final common pathway of platelet aggregation [4] it soon became the target for specific and rationally elaborated antiplatelet drugs [1].

GP IIb/IIIa are integrins, a large family of adhesion receptors, obligate heterodimers, each one composed of a large extracellular domain, a single pass transmembrane segment and a small cytoplasmic tail [22]. They exist in a low affinity state on cell surface but, upon stimulations mediated by specific intracellular signals, they convert into active state permitting linking to extracellular ligands (inside-out activation) which promotes interaction of intracellular proteins with cytoplasmic tails (outside-in activation) [23]. In the active state, the extracellular domain was shown to switch from a bent to an extended conformation [23]. In presence of calcium, the crystal structure of the extracellular domain is severely bent forming a compact "V" shape and in presence of magnesium integrin assumes an extended conformation: this is the "switchblade hypothesis" [5]. Cytoplasmic proteins that bind to the cytoplasmic tail play a critical role in initiating and propagating the bidirectional signalling events across the integrin [5]. On the other hand, inhibiting GP IIb/ IIIa either alone or with $\alpha_{\mathrm{v}} \beta_{3}$ receptor attenuates TF-induced prothrombin activation [2]. So GP IIb/IIIa inhibition may offer both antiplatelet and anticoagulant effects [3]. Progression of arterial thrombosis, mediated also by pro-coagulant activity of activated platelets, is thus doubly inhibited by GP IIb/IIIa inhibitors [2].

GP IIb/IIIa is the most abundant integrin on platelet surface and peptides containing the sequence Arginin-GlycinAspartate can inhibit interaction between this integrin and fibrinogen [24]. A number of antibodies against platelet GP IIb/IIIa were developed using animal models, particularly dogs. To prevent clearance of platelet with adhered antibodies, the Fc component was cleaved and, to limit immunologic response to the Fab fragments, a mouse/human chimeric antibody was developed called abciximab [24]. Free plasma abciximab is cleared from circulation in minutes while drugplatelet complexes persisted up to one week depending on platelet turnover [4]. Eptifibatide and tirofiban, two smallmolecules belonging to GP inhibitor class, are respectively a peptide-mimetic linking Arginin-Glycin-Aspartate sequence with a plasma half-life of 2.5 hours and a non-peptide tyrosine derivative blocking the same site with plasma half-life of 2 hours [2].

GPI must maintain more than $80 \%$ of receptor occupancy to achieve sufficient therapeutic efficacy [4]. These drugs can be administered only intravenously because, if given orally, there is a paradoxical fibrinogen binding effect related to plasmatic levels. In fact, during high plasma concentration, sufficient quantities can successfully inhibit platelets competing with physiological ligands, while during "troughs" GP IIb/IIIa would remain in extended activated state, exposing binding site to physiological agonists [25].

Thrombocytopenia and major bleeding are the more frequent complications associated with this class of drugs [26, 27]. Security and efficacy of these agents have been widely demonstrated and it should be considered that GP inhibitor induced thrombocytopenia is less related to increased risk of clinical complications than thrombocytopenia secondary to other causes (for example hematological, drug induced, septical or in relation to low output states) [26, 27].

\section{Glycoprotein Inhibitors: A Bit of History}

Safety and efficacy of bolus $(0.25 \mathrm{mg} / \mathrm{kg})$ followed by infusion $(10 \mu \mathrm{g} / \mathrm{min})$ of abciximab were evaluated in EPIC trial as early as 1994 , nevertheless it was associated to high bleeding risk and to thrombocytopenia and immune-mediated hypersensitivity [28]. The ISAR-REACT 2 trial evaluated GP inhibition in adjunct to thyenopiridine in high risk patients: abciximab administration was associated to better outcomes relying to troponin levels in patients with acute 
coronary syndromes without ST-segment elevation [29]. The use of tirofiban $(10 \mu \mathrm{g} / \mathrm{kg}$ bolus followed by $0.15 \mu \mathrm{g} / \mathrm{kg} / \mathrm{min}$ infusion) during PCI was evaluated with controversial results in TARGET (compared to abciximab) and RESTORE (compared to heparin alone) trials in 1997 - 2001 [18, 30].

Firstly Schneider proposed a high dose bolus tirofiban ( $25 \mu \mathrm{g} / \mathrm{kg}$ bolus) to improve efficacy of tirofiban during PCI, obtaining antiplatelet effects similar to abciximab with lower costs [31-33]. Similar to tirofiban, also eptifibatide dosing was adjusted since its initial employment, observing an optimal antiplatelet effect of the double bolus (two $180 \mu \mathrm{g} / \mathrm{kg}$ boluses $10 \mathrm{~min}$ apart and a continuous infusion at $2.0 \mu \mathrm{g} / \mathrm{kg} /$ min for 18 - 24 hours), as assessed in ESPRIT trial [34]. The safety and efficacy of high-dose bolus tirofiban were reported in comparison with abciximab [35-41]. Several studies compared eptifibatide to abciximab [42-44], whereas only SANTISS directly compared high-dose bolus tirofiban with double bolus eptifibatide and the superiority of tirofiban was shown [33].

\section{When and why Administer GP Inhibitors (Based on European Guidelines)?}

Current European Society of Cardiology guidelines about patients without ST segment elevation myocardial infarction (NSTEMI) consider upstream use of GPIIb/IIIa inhibitors in active ongoing ischemia among high risk patients or when double antiplatelet therapy is unfeasible. It is reasonable to use GP inhibitors in patients undergoing PCI based on angiographic results such as presence of a thrombus or troponin elevation, previous treatment with P2Y12 inhibitors, patient age and bleeding risk. Nevertheless, it is reasonable to combine GP inhibitors with dual antiplatelet therapy in patients undergoing high risk PCI and without high bleeding risk. In association with novel anticoagulant drugs such as bivalirudin GP IIb/IIIa inhibitors are not recommended because of worse outcome [9].

In STEMI, the abovementioned guidelines, declare that the role of GP inhibitors during primary PCI and the era of novel antiplatelet drugs, particularly prasugrel and ticagrelor, is not well defined. It is reasonable to use them in STEMI, similar to NSTEMI, as bailout therapy when there is angiographic evidence of a large thrombus, slow-flow or no-reflow or other particular cases. However, they are not recommended when bivalirudin is used [8]. As a consequence, in STEMI patients, periprocedural antithrombotic medication in primary PCI stepped down GP inhibitors from I to II class of recommendation, whose level of evidence was judged A for abciximab and B for high double bolus dose eptifibatide or high bolus dose tirofiban [8].

Intra-venous route should remain the standard strategy, although intra-coronary administration may be considered [8].

\section{GP Versus ADP Inhibitors}

ADP-induced platelet activation involves two receptors: $\mathrm{P} 2 \mathrm{Y} 1$ and P2Y12. Separate inhibition of one of the formers may result in a significant inhibition of platelet aggregation, although P2Y12 plays the major role. P2Y1 is coupled to a $\mathrm{G}_{\alpha \mathrm{q}}$ protein, triggering the release of calcium from internal stores, inducing platelet shape change and weak, transient ADP induced aggregation, but on the other hand it is a crucial factor for ADP or collagen induced platelet activation [45]. P2Y12 is coupled to $G_{\text {ai2 }}$ protein, a critical component of the activation pathway of GP IIb/IIIa [45]. Thienopyridine drugs, such as ticlopidine, clopidogrel and prasugrel and non-thienopyridine ticagrelor bind and inhibit P2Y12 receptor and therefore platelet aggregation [46]. Periprocedural antiplatelet therapy including these drugs has been wholly questioned, particularly considering wider use of bivalirudin as anticoagulant support for PCI [47].

Wider use of higher loading dose of clopidogrel (600 $\mathrm{mg}$ ) and the birth of new antiplatelet drugs inhibiting ADP receptor such as prasugrel and ticaglelor, definitely narrowed GP IIb/IIIa inhibitors use [8, 9, 48-51]. In STEMI patients undergoing primary PCI bivalirudin or unfractioned heparin plus GP inhibitors (600 mg loading dose of clopidogrel) was associated with a lower rate of 30-days major adverse outcomes [52].

It is of paramount importance to balance bleeding risks with risk of recurrent ischemic events. Even if some authors reported a not increased major bleeding rate in STEMI patients undergone to rescue angioplasty and GP IIb/IIIa inhibitor administration, there are discordant results [53]. Some genetic polymorphism of CYP2C19 loss of function, an hepatic enzyme contributing to the metabolism of many clinically relevant drugs, inclusive of clopidogrel, are related to drug resistance [54-57]. Recent studies showed a suboptimal platelet inhibition lasting the first 2 hours after prasugrel administration which might be obviated co-administering a bolus of GP inhibitors intravenously [58]. Therefore in the setting of STEMI patients the role of GP IIb/IIIa inhibitors is yet important, considering that intracoronary administration showed higher local receptor occupancy and improved microvascular perfusion [59-61].

Pre-hospital administration of GP IIb/IIIa inhibitors, particularly tirofiban, given very early after symptoms onset, seems associated to better revascularization outcomes [62]. Even in NSTEMI patients early administration of GP IIb/ IIIa inhibitors was associated with beneficial effects and it was continued until after procedure in patients undergoing PCI [63]. On the other hand, when novel anticoagulant drugs such as bivalirudin are administered, it was shown that use of GP IIb/IIIa inhibitors is not recommended, particularly when renal function is damaged [64].

A very recent study proposed GP IIb/IIIa inhibitors as bridging therapy for patients with drug eluting stents under- 
going surgical procedures [65].

\section{Conclusions}

GP IIb/IIIa inhibitors may still be considered effective drugs in STEMI patients and in high risk NSTEMI patients undergoing PCI. They inhibit the final common pathway of platelet aggregation, downstream to the ADP pathway regulated by P2Y12 inhibitors. They have a prompt and effective antiplatelet effect compared to ADP inhibitors and they are not influenced by patient genotypes.

Compared to thienopyridines, that have a non-reversible antiplatelet effect and a less rapid onset action, novel non-thienopyridines, cangleor and ticagrelor seem to have a promising wider use [27]. However, no head to head comparisons between these non-thienopyridines and GP IIb/IIIa inhibitors were performed and it is not probable any will be performed in the near future. Thus, a non inferiority of nonthienopyridines may not be concluded. On the other hand no ADP inhibitor showed a prompt platelet inhibition compared to GP IIb/IIIa inhibitors.

Guidelines try in general to address routes on the basis of "one concept fits all" which is definitely quite impossible in clinical conditions such as acute myocardial infarction, whether STEMI or NSTEMI, rather presenting a spectrum than a clear-cut pathology. Accordingly, not all patients' subsets may fit the currently available guidelines $[8,9]$. It is our opinion that actual data, as reviewed here, may sustain a more extensive use of GP IIb/IIIa inhibitors in patients presenting with acute coronary syndromes, strictly based on the definition for a high risk procedure: complexity, angiographic characteristics and patient's risk profile, regardless whether STEMI or NSTEMI. The positive elements one should appreciate in GP IIb/IIIa inhibitors are: efficacy, rapid onset and reversibility of action, absence of pharmacogenomic variability, pharmacoeconomic considerations and the possibility of intracoronary administration.

\section{References}

1. Ting HJ, Khasawneh FT. Platelet function and Isoprostane biology. Should isoprostanes be the newest member of the orphan-ligand family? J Biomed Sci. 2010;17(1):24.

2. Eisenberg PR, Ghigliotti G. Platelet-dependent and procoagulant mechanisms in arterial thrombosis. Int J Cardiol. 1999;68(Suppl 1):S3-10.

3. Becker RC. Thrombosis and the role of the platelet. Am J Cardiol. 1999;83(9A):3E-6E.

4. Kristensen SD, Wurtz M, Grove EL, De Caterina R, Huber K, Moliterno DJ, Neumann FJ. Contemporary use of glycoprotein IIb/IIIa inhibitors. Thromb Haemost.
2012;107(2):215-224.

5. Ma YQ, Qin J, Plow EF. Platelet integrin alpha(IIb) beta(3): activation mechanisms. J Thromb Haemost. 2007;5(7):1345-1352.

6. Valgimigli M, Minarelli M. Antiplatelet and antithrombotic treatment after primary percutaneous coronary intervention: balancing safety and efficacy. Am Heart J. 2010;160(6 Suppl):S36-41.

7. Puddu PE, Schiariti M, Bugiardini R. Glycoproteins IIb/ IIIa antagonists in acute coronary syndromes undergoing PCI: a long way to select optimal agent and route. ISRN Vasc Med 2011; 1: 1-9.

8. Steg PG, James SK, Atar D, Badano LP, BlomstromLundqvist C, Borger MA, Di Mario C, et al. ESC Guidelines for the management of acute myocardial infarction in patients presenting with ST-segment elevation. Eur Heart J. 2012;33(20):2569-2619.

9. Hamm CW, Bassand JP, Agewall S, Bax J, Boersma E, Bueno H, Caso P, et al. ESC Guidelines for the management of acute coronary syndromes in patients presenting without persistent ST-segment elevation: The Task Force for the management of acute coronary syndromes (ACS) in patients presenting without persistent ST-segment elevation of the European Society of Cardiology (ESC). Eur Heart J. 2011;32(23):2999-3054.

10. O’Rourke RA, Fuster V, Alexander RW. Hurst Il Cuore. XI Italian edition; Milano: Mc Graw Hill; 2005; 1635 1737.

11. Anderson JL, Adams CD, Antman EM, Bridges CR, Califf RM, Casey DE, Jr., Chavey WE, 2nd, et al. ACC/ AHA 2007 guidelines for the management of patients with unstable angina/non-ST-Elevation myocardial infarction: a report of the American College of Cardiology/American Heart Association Task Force on Practice Guidelines (Writing Committee to Revise the 2002 Guidelines for the Management of Patients With Unstable Angina/Non-ST-Elevation Myocardial Infarction) developed in collaboration with the American College of Emergency Physicians, the Society for Cardiovascular Angiography and Interventions, and the Society of Thoracic Surgeons endorsed by the American Association of Cardiovascular and Pulmonary Rehabilitation and the Society for Academic Emergency Medicine. J Am Coll Cardiol. 2007;50(7):e1-e157.

12. Grech ED. ABC of interventional cardiology: percutaneous coronary intervention. I: history and development. BMJ. 2003;326(7398):1080-1082.

13. Gulec S, Ozdol C, Vurgun K, Selcuk T, Turhan S, Duzen V, Temizhan A, et al. The effect of high-dose aspirin pre-treatment on the incidence of myonecrosis following elective coronary stenting. Atherosclerosis. 2008;197(1):171-176.

14. Smith SC, Jr., Feldman TE, Hirshfeld JW, Jr., Jacobs AK, Kern MJ, King SB, 3rd, Morrison DA, et al. ACC/ 
AHA/SCAI 2005 Guideline Update for Percutaneous Coronary Intervention--summary article: a report of the American College of Cardiology/American Heart Association Task Force on Practice Guidelines (ACC/AHA/ SCAI Writing Committee to Update the 2001 Guidelines for Percutaneous Coronary Intervention). Circulation. 2006;113(1):156-175.

15. Topol EJ, Byzova TV, Plow EF. Platelet GPIIb-IIIa blockers. Lancet. 1999;353(9148):227-231.

16. Bertrand ME, Simoons ML, Fox KA, Wallentin LC, Hamm CW, McFadden E, De Feyter PJ, Specchia G, Ruzyllo W; Task Force on the Management of Acute Coronary Syndromes of the European Society of Cardiology. Management of acute myocardial infarction in patients presenting with ST-segmente elevation. The task force on the management of acute coronay syndromes of the European Society of Cardiology. Eur Heart J 2002; 23: 1089-1140.

17. Braunwald E, Antman EM, Beasley JW, Califf RM, Cheitlin MD, Hochman JS, Jones RH, et al. ACC/AHA 2002 guideline update for the management of patients with unstable angina and non-ST-segment elevation myocardial infarction--summary article: a report of the American College of Cardiology/American Heart Association task force on practice guidelines (Committee on the Management of Patients With Unstable Angina). J Am Coll Cardiol. 2002;40(7):1366-1374.

18. Topol EJ, Moliterno DJ, Herrmann HC, Powers ER, Grines CL, Cohen DJ, Cohen EA, et al. Comparison of two platelet glycoprotein IIb/IIIa inhibitors, tirofiban and abciximab, for the prevention of ischemic events with percutaneous coronary revascularization. N Engl J Med. 2001;344(25):1888-1894.

19. Schuhlen H, Hadamitzky M, Walter H, Ulm K, Schomig A. Major benefit from antiplatelet therapy for patients at high risk for adverse cardiac events after coronary Palmaz-Schatz stent placement: analysis of a prospective risk stratification protocol in the Intracoronary Stenting and Antithrombotic Regimen (ISAR) trial. Circulation. 1997;95(8):2015-2021.

20. Bertrand ME, Legrand V, Boland J, Fleck E, Bonnier J, Emmanuelson H, Vrolix M, et al. Randomized multicenter comparison of conventional anticoagulation versus antiplatelet therapy in unplanned and elective coronary stenting. The full anticoagulation versus aspirin and ticlopidine (fantastic) study. Circulation. 1998;98(16):1597-1603.

21. Gregorini L, Marco J, Fajadet J, Bernies M, Cassagneau B, Brunel P, Bossi IM, et al. Ticlopidine and aspirin pretreatment reduces coagulation and platelet activation during coronary dilation procedures. J Am Coll Cardiol. 1997;29(1):13-20.

22. Yang J, Ma YQ, Page RC, Misra S, Plow EF, Qin J. Structure of an integrin alphaIIb beta3 transmem- brane-cytoplasmic heterocomplex provides insight into integrin activation. Proc Natl Acad Sci U S A. 2009;106(42):17729-17734.

23. Kurtz L, Kao L, Newman D, Kurtz I, Zhu Q. Integrin alphaIIbbeta3 inside-out activation: an in situ conformational analysis reveals a new mechanism. J Biol Chem. 2012;287(27):23255-23265.

24. Schneider DJ. Anti-platelet therapy: glycoprotein IIbIIIa antagonists. Br J Clin Pharmacol. 2011;72(4):672682.

25. Armstrong PC, Peter K. GPIIb/IIIa inhibitors: from bench to bedside and back to bench again. Thromb Haemost. 2012;107(5):808-814.

26. Viswanathan G, Kidambi A, Nelson A, Mayurathan G, Hardy J, Kesteven P, Zaman A. Glycoprotein IIb/IIIa inhibitor associated severe thrombocytopenia in patients with coronary artery disease: Clinical course and outcomes. Platelets. 2012;23(3):224-228.

27. Ji X, Hou M. Novel agents for anti-platelet therapy. J Hematol Oncol. 2011;4:44.

28. Use of a monoclonal antibody directed against the platelet glycoprotein IIb/IIIa receptor in high-risk coronary angioplasty. The EPIC Investigation. N Engl J Med. 1994;330(14):956-961.

29. Kastrati A, Mehilli J, Neumann FJ, Dotzer F, ten Berg $\mathrm{J}$, Bollwein $\mathrm{H}$, Graf $\mathrm{I}$, et al. Abciximab in patients with acute coronary syndromes undergoing percutaneous coronary intervention after clopidogrel pretreatment: the ISAR-REACT 2 randomized trial. JAMA. 2006;295(13):1531-1538.

30. Effects of platelet glycoprotein IIb/IIIa blockade with tirofiban on adverse cardiac events in patients with unstable angina or acute myocardial infarction undergoing coronary angioplasty. The RESTORE Investigators. Randomized Efficacy Study of Tirofiban for Outcomes and REstenosis. Circulation. 1997;96(5):1445-1453.

31. Schneider DJ, Herrmann HC, Lakkis N, Aguirre F, Wan Y, Aggarwal A, Kabbani SS, et al. Enhanced early inhibition of platelet aggregation with an increased bolus of tirofiban. Am J Cardiol. 2002;90(12):1421-1423.

32. Schiariti M, Saladini A, Missiroli B, Papalia F, Cuturello D, Puddu PE, Gaudio C. Safety of downstream high-dose tirofiban bolus among 1578 patients undergoing percutaneous coronary intervention: the Sant'ANna TIrofiban Safety study. J Cardiovasc Med (Hagerstown) 2010; 11: 250-259.

33. Schiariti M, Saladini A, Cuturello D, Missiroli B, Puddu PE. Long-term efficacy of high-dose tirofiban versus double-bolus eptifibatide in patients undergoing percutaneous coronary intervention. J Cardiovasc Med (Hagerstown). 2011;12(1):29-36.

34. Novel dosing regimen of eptifibatide in planned coronary stent implantation (ESPRIT): a randomised, placebo-controlled trial. Lancet. 2000;356(9247):2037-2044. 
35. Danzi GB, Sesana M, Capuano C, Mauri L, Berra Centurini $\mathrm{P}$, Baglini R. Comparison in patients having primary coronary angioplasty of abciximab versus tirofiban on recovery of left ventricular function. Am J Cardiol. 2004;94(1):35-39.

36. Danzi GB, Capuano C, Sesana M, Baglini R. Safety of a high bolus dose of tirofiban in patients undergoing coronary stent placement. Catheter Cardiovasc Interv. 2004;61(2):179-184.

37. Valgimigli M, Percoco G, Barbieri D, Ferrari F, Guardigli G, Parrinello G, Soukhomovskaia O, et al. The additive value of tirofiban administered with the highdose bolus in the prevention of ischemic complications during high-risk coronary angioplasty: the ADVANCE Trial. J Am Coll Cardiol. 2004;44(1):14-19.

38. Danzi GB, Sesana M, Capuano C, Mauri L, Predolini $\mathrm{S}$, Baglini R. Downstream administration of a high-dose tirofiban bolus in high-risk patients with unstable angina undergoing early percutaneous coronary intervention. Int J Cardiol. 2006;107(2):241-246.

39. Bolognese L, Falsini G, Liistro F, Angioli P, Ducci K, Taddei T, Tarducci R, et al. Randomized comparison of upstream tirofiban versus downstream high bolus dose tirofiban or abciximab on tissue-level perfusion and troponin release in high-risk acute coronary syndromes treated with percutaneous coronary interventions: the EVEREST trial. J Am Coll Cardiol. 2006;47(3):522-528.

40. Bilsel T, Akbulut T, Yesilcimen K, Terzi S, Sayar N, Dayi SU, Akgoz H, et al. Single high-dose bolus tirofiban with high-loading-dose clopidogrel in primary coronary angioplasty. Heart Vessels. 2006;21(2):102-107.

41. Gunasekara AP, Walters DL, Aroney CN. Comparison of abciximab with "high-dose" tirofiban in patients undergoing percutaneous coronary intervention. Int J Cardiol. 2006;109(1):16-20.

42. O'Shea JC, Hafley GE, Greenberg S, Hasselblad V, Lorenz TJ, Kitt MM, Strony J, et al. Platelet glycoprotein IIb/IIIa integrin blockade with eptifibatide in coronary stent intervention: the ESPRIT trial: a randomized controlled trial. JAMA. 2001;285(19):2468-2473.

43. Giugliano RP, White JA, Bode C, Armstrong PW, Montalescot G, Lewis BS, van 't Hof A, et al. Early versus delayed, provisional eptifibatide in acute coronary syndromes. N Engl J Med. 2009;360(21):2176-2190.

44. Marmur JD, Poludasu S, Lazar J, Cavusoglu E. Longterm mortality after bolus-only administration of abciximab, eptifibatide, or tirofiban during percutaneous coronary intervention. Catheter Cardiovasc Interv. 2009;73(2):214-221.

45. Hechler B, Gachet C. P2 receptors and platelet function. Purinergic Signal. 2011;7(3):293-303.

46. Sharma RK, Voelker DJ, Sharma R, Reddy HK, Dod H, Marsh JD. Evolving role of platelet function testing in coronary artery interventions. Vasc Health Risk Manag.
2012;8:65-75.

47. Desai NR, Bhatt DL. The state of periprocedural antiplatelet therapy after recent trials. JACC Cardiovasc Interv. 2010;3(6):571-583.

48. Dangas G, Mehran R, Guagliumi G, Caixeta A, Witzenbichler B, Aoki J, Peruga JZ, et al. Role of clopidogrel loading dose in patients with ST-segment elevation myocardial infarction undergoing primary angioplasty: results from the HORIZONS-AMI (harmonizing outcomes with revascularization and stents in acute myocardial infarction) trial. J Am Coll Cardiol. 2009;54(15):14381446.

49. Lotrionte M, Biondi-Zoccai GG, Agostoni P, Abbate A, Angiolillo DJ, Valgimigli M, Moretti C, et al. Metaanalysis appraising high clopidogrel loading in patients undergoing percutaneous coronary intervention. Am J Cardiol. 2007;100(8):1199-1206.

50. Wiviott SD, Braunwald E, McCabe CH, Montalescot G, Ruzyllo W, Gottlieb S, Neumann FJ, et al. Prasugrel versus clopidogrel in patients with acute coronary syndromes. N Engl J Med. 2007;357(20):2001-2015.

51. Wiviott SD, Trenk D, Frelinger AL, O’Donoghue M, Neumann FJ, Michelson AD, Angiolillo DJ, et al. Prasugrel compared with high loading- and maintenancedose clopidogrel in patients with planned percutaneous coronary intervention: the Prasugrel in Comparison to Clopidogrel for Inhibition of Platelet Activation and Aggregation-Thrombolysis in Myocardial Infarction 44 trial. Circulation. 2007;116(25):2923-2932.

52. Paraskevas KI, Athyros VG, Briana DD, Kakafika AI, Karagiannis A, Mikhailidis DP. Statins exert multiple beneficial effects on patients undergoing percutaneous revascularization procedures. Curr Drug Targets. 2007;8(8):942-951.

53. Shugman IM, Hsieh V, Cheng S, Parikh D, Tobing D, Wouters N, van der Vijver R, et al. Safety and efficacy of rescue angioplasty for ST-elevation myocardial infarction with high utilization rates of glycoprotein $\mathrm{IIb} / \mathrm{IIIa}$ inhibitors. Am Heart J. 2012;163(4):649-656 e641.

54. Beitelshees AL. Personalised antiplatelet treatment: a RAPIDly moving target. Lancet. 2012;379(9827):16801682.

55. Jeong YH, Bliden KP, Park Y, Tantry US, Gurbel PA. Pharmacogenetic guidance for antiplatelet treatment. Lancet. 2012;380(9843):725; author reply 725-726.

56. Scott SA, Sangkuhl K, Gardner EE, Stein CM, Hulot JS, Johnson JA, Roden DM, et al. Clinical Pharmacogenetics Implementation Consortium guidelines for cytochrome P450-2C19 (CYP2C19) genotype and clopidogrel therapy. Clin Pharmacol Ther. 2011;90(2):328-332.

57. Beitelshees AL, Horenstein RB, Vesely MR, Mehra MR, Shuldiner AR. Pharmacogenetics and clopidogrel response in patients undergoing percutaneous coronary interventions. Clin Pharmacol Ther. 2011;89(3):455-459. 
58. Valgimigli M, Tebaldi M, Campo G, Gambetti S, Bristot L, Monti M, Parrinello G, et al. Prasugrel versus tirofiban bolus with or without short post-bolus infusion with or without concomitant prasugrel administration in patients with myocardial infarction undergoing coronary stenting: the FABOLUS PRO (Facilitation through Aggrastat By drOpping or shortening Infusion Line in patients with ST-segment elevation myocardial infarction compared to or on top of PRasugrel given at loading dOse) trial. JACC Cardiovasc Interv. 2012;5(3):268277.

59. Wang Y, Wu B, Shu X. Meta-analysis of randomized controlled trials comparing intracoronary and intravenous administration of glycoprotein IIb/IIIa inhibitors in patients with ST-elevation myocardial infarction. Am J Cardiol. 2012;109(8):1124-1130.

60. Soon D, Ho HH, Loh KK, Ooi YW, Foo D, Jafary FH, Ong PJ. Clinical outcomes of intracoronary eptifibatide bolus only versus intracoronary bolus and intravenous infusion of eptifibatide in primary percutaneous coronary intervention. Acute Card Care. 2012;14(1):42-44.

61. Desch S, Siegemund A, Scholz U, Adam N, Eitel I, de Waha S, Furnau G, et al. Platelet inhibition and GP IIb/ IIIa receptor occupancy by intracoronary versus intravenous bolus administration of abciximab in patients with
ST-elevation myocardial infarction. Clin Res Cardiol. 2012;101(2):117-124.

62. Hermanides RS, van Werkum JW, Ottervanger JP, Breet NJ, Gosselink AT, van Houwelingen KG, Dambrink JH, et al. The effect of pre-hospital glycoprotein IIb-IIIa inhibitors on angiographic outcome in STEMI patients who are candidates for primary PCI. Catheter Cardiovasc Interv. 2012;79(6):956-964.

63. Boersma E, Akkerhuis KM, Theroux P, Califf RM, Topol EJ, Simoons ML. Platelet glycoprotein IIb/IIIa receptor inhibition in non-ST-elevation acute coronary syndromes: early benefit during medical treatment only, with additional protection during percutaneous coronary intervention. Circulation. 1999;100(20):2045-2048.

64. Acharji S, Baber U, Mehran R, Fahy M, Kirtane AJ, Lansky AJ, Stone GW. Prognostic significance of elevated baseline troponin in patients with acute coronary syndromes and chronic kidney disease treated with different antithrombotic regimens: a substudy from the ACUITY trial. Circ Cardiovasc Interv. 2012;5(2):157-165.

65. Ben Morrison T, Horst BM, Brown MJ, Bell MR, Daniels PR. Bridging with glycoprotein IIb/IIIa inhibitors for periprocedural management of antiplatelet therapy in patients with drug eluting stents. Catheter Cardiovasc Interv. 2012;79(4):575-582. 